\title{
TSUNAMI-INDUCED HYDRODYNAMICS AND SCOUR AROUND STRUCTURES
}

\author{
Ravindra Jayaratne, University of East London, r.jayaratne@uel.ac.uk \\ Mara Nicholas, J Murphy \& Sons Ltd., maranicholas@murphygroup.co.uk \\ Behnaz Ghodoosipour, University of Ottawa, bghod068@uottawa.ca \\ Sophie Mugnaini, University of East London, u1618571@uel.ac.uk \\ Ioan Nistor, University of Ottawa, inistor@uottawa.ca \\ Tomoya Shibayama, Waseda University, shibayama@waseda.jp
}

\section{INTRODUCTION}

The complex hydrodynamics during a tsunami event can significantly affect the structural integrity of buildings. The resulting hydrodynamic forces are influenced by various fluid parameters such as the fluid density, flow velocity and depth, as well as by the structure's geometry. Hydrodynamic forces induced by tsunami pressures and velocities are particularly important, as they occur usually around a coastal defence structure or a building and as a result, they affect the structural integrity of the structure (Chinnarasri et al, 2013). The 2011 Japan post-tsunami field survey of Chock et al. (2013) indicated that lateral pressures, uplift pressures and surge flow from the tsunami produced hydrodynamic forces responsible for the destruction of many structures along the Tohoku coastline. The associated hydrodynamic parameters of a tsunami such as pressures and velocities also influence the tsunami-induced scour around buildings. Nicholas et al. (2016) stated that the tsunami-induced hydrodynamic velocity was a crucial factor in producing soil-scour around building structures.

\section{NUMERICAL MODELLING}

A numerical model was developed using OpenFOAM v2.3.0 (Open Source Field Operation and Manipulation), an open-source CFD-toolbox produced by OpenCFD Ltd. (OpenFOAM, 2014) in order to obtain tsunami-induced hydrodynamics parameters for simulated model buildings. The model uses three-dimensional RANS equations as the governing equations for incompressible fluids, as follows:

Continuity Equation:

$\frac{\partial u_{x}}{\partial x}+\frac{\partial u_{y}}{\partial y}+\frac{\partial u_{z}}{\partial z}=0$

Momentum Equations:

$$
\begin{aligned}
\bar{u} \frac{\partial \bar{u}}{\partial x}+\bar{v} \frac{\partial \bar{u}}{\partial y}+\bar{w} \frac{\partial \bar{u}}{\partial z}= & -\frac{1}{\rho} \frac{\partial \bar{\rho}}{\partial x}+g_{x}+v\left(\frac{\partial^{2} \bar{u}}{\partial x^{2}}+\frac{\partial^{2} \bar{u}}{\partial y^{2}}+\frac{\partial^{2} \bar{u}}{\partial z^{2}}\right) \\
& -\left(\frac{\overline{\partial u^{\prime 2}}}{\partial x}+\frac{\overline{\partial u^{\prime} v^{\prime}}}{\partial y}+\frac{\overline{\partial u^{\prime} w^{\prime}}}{\partial z}\right) \\
\bar{u} \frac{\partial \bar{v}}{\partial x}+\bar{v} \frac{\partial \bar{v}}{\partial y}+\bar{w} \frac{\partial \bar{v}}{\partial z} & =-\frac{1}{\rho} \frac{\partial \bar{\rho}}{\partial y}+g_{x}+v\left(\frac{\partial^{2} \bar{v}}{\partial x^{2}}+\frac{\partial^{2} \bar{v}}{\partial y^{2}}+\frac{\partial^{2} \bar{v}}{\partial z^{2}}\right) \\
& -\left(\frac{\overline{\partial v^{\prime 2}}}{\partial y}+\frac{\overline{\partial u^{\prime} v^{\prime}}}{\partial x}+\frac{\overline{\partial u^{\prime} w^{\prime}}}{\partial z}\right) \\
\bar{u} \frac{\partial \bar{w}}{\partial x}+\bar{v} \frac{\partial \bar{w}}{\partial y}+\bar{w} \frac{\partial \bar{w}}{\partial z} & =-\frac{1}{\rho} \frac{\partial \bar{\rho}}{\partial z}+g_{x}+v\left(\frac{\partial^{2} \bar{w}}{\partial x^{2}}+\frac{\partial^{2} \bar{w}}{\partial y^{2}}+\frac{\partial^{2} \bar{w}}{\partial z^{2}}\right) \\
& -\left(\frac{\partial w^{\prime 2}}{\partial z}+\frac{\overline{\partial w^{\prime} v^{\prime}}}{\partial y}+\frac{\overline{\partial u^{\prime} w^{\prime}}}{\partial x}\right)
\end{aligned}
$$

where $\bar{u}, \bar{v}, \bar{w}$ and $\bar{\rho}$ are the mean velocity components and $u^{\prime}, v^{\prime}$ and $w^{\prime}$ are instant velocities in the $\mathrm{x}, \mathrm{y}$ and $\mathrm{z}$ directions respectively. $\rho$ is the fluid density, $t$ is the time, and $\mathrm{g}$ is the gravitational acceleration.
The tsunami-hydrodynamic laboratory experiments carried out by Al-Faesly et al. (2012) at the National Research Council Canada (NRC) were replicated numerically in order to verify the performance of the OpenFOAM numerical model. A square-cross section (L0.305 $\times \mathrm{W} 0.305 \times \mathrm{H} 1.0 \mathrm{~m})$ was used as the standard model in the numerical simulations. The hydraulic conditions produced where impounding depths of $0.55 \mathrm{~m}, 0.85 \mathrm{~m}$, and $1.15 \mathrm{~m}$ at the upstream end respectively. The pressures and velocities were measured at the toe of the structure for depths at $0.20 \mathrm{~m}, 0.30 \mathrm{~m}$ and $0.50 \mathrm{~m}$. The detailed experimental set-up and test program are provided in AlFaesly et al. (2012). Figure 1 illustrates an example of a numerical simulation carried out using the OpenFOAM model. The velocity contours shown in Fig. 1 corresponds to the instant of $1.4 \mathrm{~s}$ from the opening of the swing gate.

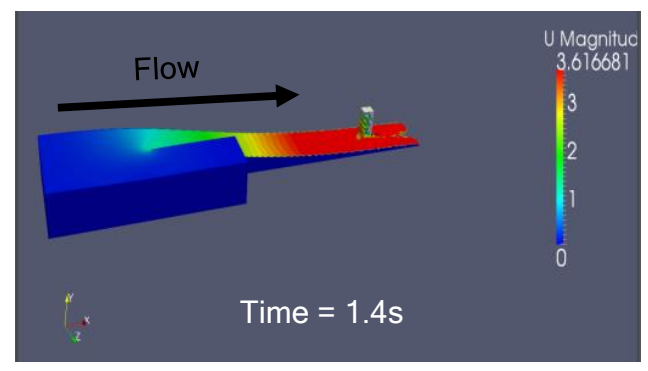

Figure 1 - Instantaneous velocity obtained using the OpenFOAM model.

VERIFICATION OF NUMERICAL MODEL WITH EXPERIMENTAL RESULTS (AL-FAESLY ET AL., 2012) Figure 2 shows the comparison between the experimental (Al-Faesly et al., 2012) and OpenFOAM numerical results for the time history of the pressure at the front face of the structure and at $0.05 \mathrm{~m}$ height from the base of the square-section structural model, for an impounding upstream water depth of $0.85 \mathrm{~m}$. The results indicate that the numerical model can reproduce the experimental data.

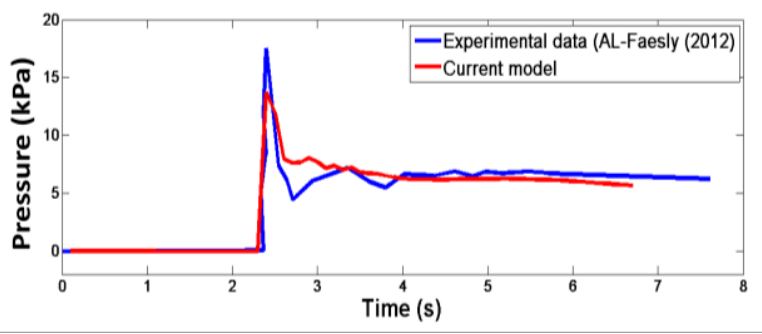

Figure 2 - Comparison of experimental data (Al-Faesly et al., 2012) and current numerical model.

EXPERIMENTAL MODELLING AT UNIVERSITY OF EAST LONDON (UEL)

A series of comprehensive small-scale tsunami-induced scour experiments were performed at the Hydraulics 
Laboratory of UEL in order to reproduce a damaged rectangular building in Minamisanriku, Miyagi Prefecture, following the 2011 Tohoku tsunami. A dam breaking wave was reproduced to impact the L0.22 $\times$ W $0.067 \times \mathrm{H} 0.102 \mathrm{~m}$ wooden model building of $1: 150$ scale within a channel section of $7.0 \mathrm{~m}$ long and $0.305 \mathrm{~m}$ wide by lifting a gate manually. The bathymetry of the Japanese coastline (1:50 beach slope) was reproduced of an upstream and downstream water levels of $0.30 \mathrm{~m}$ and $0.015 \mathrm{~m}$ respectively. A bucket full of $0.22 \mathrm{~mm}$ sand was located at the front of the building so that maximum scour depth could be measured using a manually-operated point gauge to a degree of $0.1 \mathrm{~mm}$ accuracy. A digital video camera with $50 \mathrm{fps}$ was used to capture the water surface elevations at the toe of building structure. Figure 3 illustrates the detailed scour experimental set-up at UEL.

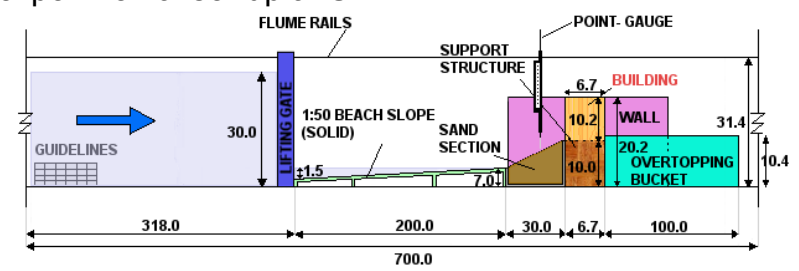

Figure 3 - Tsunami-induced scour experimental set-up at UEL (All dimensions are in $\mathrm{cm}$ ).

An example of measured scour holes and extent (plan view) in seaward width of the building are shown in Fig. 4.

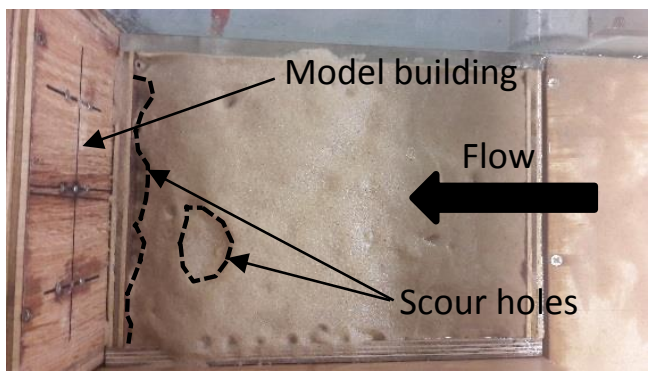

Figure 4 - Scour holes generated in the seaward width of the model building structure (Test case 1, Downstream water depth $=0.015 \mathrm{~m})$.

\section{COMPARISON OF SCOUR DEPTHS}

The hydrodynamic output such as pressures, velocities and water levels at the middle and toe of the building were obtained using OpenFOAM numeral model with the intention of using these parameters in relative scour depth (Z) predictive model (Eq. 5) of Nicholas et al. (2016).

$\frac{Z}{B_{h}} 16\left(\frac{g B_{h}}{C V^{2}}\right)^{-1}$

where $B_{h}$ is half seaward width of building, $C$ is DarcyWeisbach friction factor, $V$ is flow velocity and $g$ is gravitational acceleration.

The comparisons results were obtained for downstream water depth of $0.015 \mathrm{~m}$ above the bottom of the channel. The velocity and pressure values obtained by the OpenFOAM model were incorporated into the scour predictive model of Nicholas et al. (2016). The representative scour depth comparisons were performed at 1:150 scale between the laboratorymeasured (UEL), field, predictive model of Nicholas et al. (2016) with experimental conditions and the same predictive model using the numerical hydrodynamic conditions of OpenFoam model. The results indicate that the laboratory-measured $(8.8 \mathrm{~mm})$ and predictive model with experimental conditions $(8.4 \mathrm{~mm})$ were reasonably comparable with the scaled-down field value of $13 \mathrm{~mm}$. However, scour depth obtained using numerical hydrodynamic conditions under-predicts field and laboratory scour depths. It is expected that numerical model has some limitation of incorporating roughness coefficients in field and laboratory scales. The trends in the results indicated that higher inundation depths and flow velocities resulted in higher predictive scour depths.

Figure 5 depicts relative scour time history generated using predicted hydrodynamic conditions of OpenFOAM model. The velocity values from $t=1.4 \mathrm{~s}$ was used as the starting time of wave-structure interaction. It was observed that the velocity decreased sharply after $1.4 \mathrm{~s}$ and remained relatively constant thereafter. This indicated that the initial wave interaction on the building was at its peak hydrodynamic conditions; i.e. both high pressures and flow velocities.

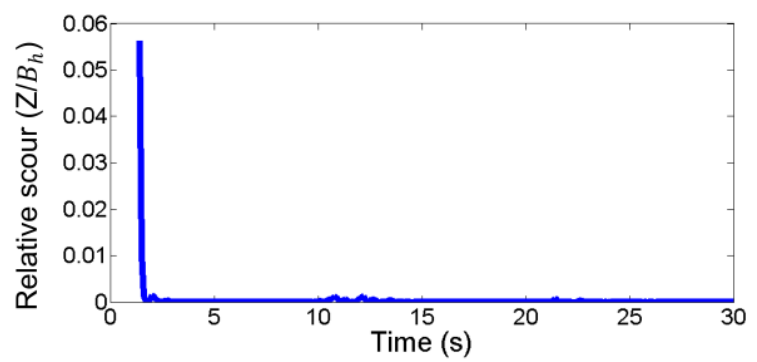

Figure 5 - Time history of relative scour depth produced using Nicholas et al. (2016) model with hydrodynamic conditions of OpenFoam numerical model.

\section{CONCLUSIONS}

Numerical, experimental, theoretical modelling and post-tsunami field data were used to investigate the hydrodynamic conditions and representative scour depths at the seaward of building structures subjected to tsunami waves. It is concluded that tsunami-induced hydrodynamic conditions affect the outcome of predictive scour depth around buildings. At peak hydrodynamic conditions it is expected that scour depth should be at its peak. The analysis indicates that understanding the tsunami hydrodynamic conditions can result in better scour prediction and hence a better understanding of the design of building foundations. The ICCE 2018 presentation will include discussion of numerical modelling, laboratory test cases at UEL, design recommendations for resilience of buildings and limitations of numerical, experimental and theoretical models.

\section{REFERENCES}

Al-Faesly, Palermo, Nistor, Cornett (2012): Experimental modelling of extreme hydrodynamic forces on structural models, International Journal of Protective Structures, SAGE Publications, 3(4), pp.477-505.

Chinnarasri, Thanasisathit, Ruangrassamee, Weesakul, Lukkunaprasit (2013): The impact of tsunami-induced bores on buildings, Maritime Engineering, ICE, 166 (MA1), pp.14-24. Chock, Robertson, Kriebel, Francis, Nistor (2013): Tohoku Japan Tsunami of March 11, 2011 Performance of Structures. Virginia: ASCE.

Nicholas, Jayaratne, Suzuki, Shibayama (2016): A predictive model for scour depth of coastal building failures due to tsunamis, $35^{\text {th }}$ ICCE, Antalya, Turkey.

OpenFOAM (2014): Open Source Field Operation and Manipulation, https://www.openfoam.com/documentation. 